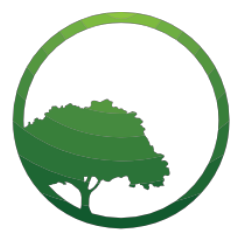

Business \& Social Science IJRBS

\section{Research in Business and Social Science}

IJRBS Vol 8 No 2, ISSN: 2147-4478

Contents available at www.ssbfnet.com/ojs

\title{
Improving Ergonomic Conditions at Hospitality Industry
}

Mune Moğol Sever

PhD., Tourism Faculty, Anadolu University, Eskişehir Turkey, +90222 33505 80-2123

ORCID ID: 0000-0003-4706-5859

\begin{abstract}
This study aims to investigate ergonomic risk factors and improve the process in hotel enterprises. The research focused on the main operational process such as food preparation, material supply, and warehouse, in the kitchen, housekeeping and warehouse departments. In the first step, a checklist is prepared according to ILO, OSHA, NIOSH and IEA documents. In this checklist job tasks, workstations and working environment are subject to the study. After controlled by industry experts checklist implemented and results show that there are some ergonomic risk factors in the kitchen. In order to improve the ergonomic conditions $2^{3}$, (3 factors, 2 level) factorial design was put into practice. Results show that the greatest effect is caused by Factor 2 (presence of underfoot mat) comes first, Factor 1 (height of the workbench is at elbow level) comes second and Factor 3 (job rotation) comes third.
\end{abstract}

Key words: Ergonomics, factorial design, hotel ergonomics, hospitality industry

JEL classification: M11,M19, D24

Submitted: 04.03.2019 - Accepted: 21.03.2019

\section{Introduction}

Ergonomics is a science discipline used by Wojciech Jastrzebowski in 1857 for the first time and it is based on the improvement of the relationship between the employees and work environment.

Even though ergonomics is applied in many fields for manufacturing enterprises, it remained limited to restaurants, work safety, accidents, and injuries for tourism enterprises and it is seen that there are not enough studies regarding proactive measures and determining the risks beforehand.

This study aims to determine and the ergonomic risks and improve the physical conditions for jobs under risks. The checklist which has been prepared using International Labor Organization (ILO), Occupational Safety and Health Administration (OSHA), The National Institute for Occupational Safety and Health (NIOSH) and International Ergonomics Association (IEA) documents is drawn up by taking opinions of experts in the industry. Thus the risk points are determined. This list has been implemented for all sectional tasks at a 5- 


\section{Mogol Sever / International Journal of Research in Business and Social Science,}

Vol 8 No 2, 2019 ISSN: 2147-4486

star hotel and the workstations and the environment have been analyzed. Determination of risks would prevent physical deformation as a proactive approach and increase organizational productivity by saving labor and time.

In the following sections study will be explained with detailed with the experimental design and how the system improvement conducted.

\section{Literature Review}

While ergonomics is a frequently benefited science in many fields of manufacturing businesses, the tourism enterprises though being labor-intensive businesses by their nature, are not sufficiently aware of it yet. Therefore, it is important for the concept of ergonomics to be included and implemented in this labor-intensive sector for the sake of employees to work in a more comfortable environment and be more productive. The study by Kalkis, Roja \& Kalkis (2014) to determine the physical workload that hotel cleaning staff are exposed to while cleaning the office was conducted with the participation of 23 female personnel. Eight basic jobs were taken into consideration within the scope of the study. These are cleaning works at water closets, showers, sinks, cloakrooms, corridors, and conference halls. They have tried to determine the physical loads and strain during these work processes. A questionnaire was conducted with the participants before the research to get their opinions regarding ergonomic risks, work conditions, and the parts of the body that are affected by physical loads and how they affect. In the research, the risks posed by lifting, holding and carrying the heavy load by hands were determined by using the method of Key Indicator Method for Assessing Basic Ergonomic Risks (KIM). The risk category has been determined by comparing the obtained risk values to the figures specified in the standards of American NIOSH organization and ISO 28996. Accordingly, it is concluded that 8 jobs subjecting to examination are at low and medium difficulty levels. Another criterion of the study is the measurement of Early Warning Control of Risk Exposure (Quick Exposure Check-QEC) and Heart Rate Monitoring. The specified standards have been included in the QEC and the QEC has been found to be at a medium level in the motions of shoulders during shower and cloakroom cleaning and at low levels in all other values at the end of the measurements. When heart rate measurements have been considered, it has been concluded that these works fall into the light-work category. The study has been conducted by only taking mathematical calculations such as KIM, QEC, and HRM into consideration but without considering the working conditions. Stress, climatic state, fatigue, monotony, noise, vibration etc. have not been taken into consideration.

In a study conducted by Rahman, Jaffar, Hassan, Ngali \&Pauline (2017) in Malaysia with 65 participants at various hotels, the data were collected through observation by using Workplace Ergonomic Risk Assessment-WERA and QEC (Quick Exposure Checklist) methods. These observations resulted in that some parts of the body such as back and feet are strained and either the jobs should be redesigned or changed. Considering the QEC values, it has been concluded that some jobs should be urgently changed to reduce the risks that the cleaning staff is exposed to. Again, the work environment has not been analyzed in this study and no scientific methods have been used to determine the ergonomic risk points.

Keyserling, Brouwer \& Silverstein (1992) developed a checklist as a part of joint labor management ergonomics intervention programs to determine ergonomic risks related to awkward postures of legs, trunk, and neck. This checklist is developed for manufacturing industry (automotive jobs) and not applicable for the service industry.Demsey and Filiaggi (2006) conducted a study on 100 restaurant wait staff who are subjected to the musculoskeletal discomfort. In their study, $42 \%$ musculoskeletal, the lower back area (18\%) and shoulder (11\%) symptoms were experienced. Wills et al. (2016) analysed physical discomfort and ergonomic stress that restaurant server's exposure. As researchers analysed upper back is the greatest discomfort (55\%) body region during the shift. Gentzler and Smither (2012) try to assess the risk of injuries and accidents from conducting various tasks in the restaurant, specifically carrying/lifting, table management, and polishing silverware for restaurant staff. They conducted the study on nine staff and measure Cumulative Trauma Disorders (CTD) on the musculoskeletal system. Besides, musculoskeletal disorders and awkward posture at restaurant and hospitality industry has been studied by various scholars (Gogri, Josh, Dabadgha, Rairikar, Shyam\& Sancheti, 2017; Liu, Wang, Hwan, Lee\& Chen, 2011; Haukka, Leino-Arjas, Solovieva, Ranta, Viikari- Juntura.\&Riihimäki, 2006; Syed-Ali, Kamat, \& Mohamed, 2018; Parmar and Dalal 2017; 


\section{Mogol Sever / International Journal of Research in Business and Social Science,} Vol 8 No 2, 2019 ISSN: 2147-4486

Mehlum, Kristensen, Kjuus \&Wergeland, 2008; and Chyuan, Du, Yeh\& Li, 2004). In Kapulainen (2010) study ergonomic analysis has been implemented for a famous restaurant chain in Finland. In this study researcher try to analyze posture of personnel while doing the job, lifting heavy materials, working conditions such as air quality, the noise of the working environment and ergonomic conditions of materials are used. Study properly analyzed working conditions for personnel and working environment but is lack of finding improvement in an ergonomic risk area. [He/She] aims to [determine] the ergonomic improvement needs of restaurant employees at a famous restaurant in Finland (Jyväskylä) and offer solutions to meet these needs. The ideas regarding postures of employees working in the bar and kitchen of the restaurant during work, analysis of the environment's air in terms of oxygen and noise in situations like lifting heavy loads etc. and improvement of the equipment are compiled. While [he/she] was good in the analysis of job and environment, [he/she] came short and was insufficient in respect of improvement.

While analyzing studies conducted in ergonomics some of the measurement such as WERA, QEC, KIM, HRM have emerged. Though studies try to find ergonomic discomfort and stress factors they are lack of finding solutions and improvement. When examining tourism industries research, studies conducted in the part of a hotel or a restaurant. It is encountered studies have not holistic approach and are handled an enterprise with its working environment, workstations, job tasks. This study tries to analyze each job tasks handled in a hotel that has a very short cycle time and heavy working conditions. However, it is necessary to conduct an improvement study to determine ergonomic risk points and decrease the risks. It is also observed that the tourism studies have been conducted only at certain parts of hotels but not all around the hotel and work environment and workbenches (workstations) have not been addressed along with the jobs. A checklist which would facilitate the analysis of all jobs at the hotel requiring compelling pace, that are related to heavy loads, repetitive and having a short (Cycle time) is generated and this list would be used in numerous establishments such as restaurants, hospitals and cleaning companies.

\section{Research and Methodology}

A checklist was made within the scope of research. This list is prepared as an initial screen of the tool. Documents benefited from during the preparation of checklist are below:

i. Work Improvement for Small Enterprises Program (2018) of ILO

ii. Ergonomics and Trauma Injuries: basics for housekeeper manager document of disorder OSHA

iii. Ergonomics Guideline in 2009 IEA

iv. Elements of Ergonomic Program (1998), Tray 5-A. General Ergonomics Risk Analysis Checklist NIOSH.

The prepared list has been rearranged by taking expert opinions in the sector. Thus, the checklist was put into its final form. While preparing this checklist the activities at the basic operational units of a 5 -star hotel such as food-beverage and housekeeping departments and food preparation, storage and material supply activities were taken into consideration. In the period of 1 week, the following three points were reviewed at the said hotel of which subject to this study:
i. Analyzing the job in terms of Ergonomics - Task Analysis
ii. Analyzing workstations/workbenches- Workstation Analysis
iii. Analyzing environment - Working Environment and Layout (Environmental Analysis)

The data obtained by observation were reviewed and the areas to be improved were determined. An experimental design was implemented for improvement in these areas. $2^{3}$ Full factorial design was implemented. The study is composed of the following steps:

i. Developing Check List

ii. Analyzing jobs, workstation and environment 
iii. System improvement

All steps are explained respectively.

\section{Developing Check List}

At this step, a checklist composed of three sections was developed. This list analyses the ergonomic risk points of all activities performed by the personnel in housekeeping, restaurant kitchen, and storage, who are responsible for procurement of materials. Ergonomic risks for the job of each person are determined in this list and all risky jobs are marked with a checkmark. At the end of the study, it is tried to analyze the job in the first part of the list, the workbench, station in the second part and the environment in the last part. The first step is the analysis of the job. In the second step, workstations and workbenches are analyzed and finally, the working environment is analyzed. The checklist, reference values and positions are as follows:

Task analysis

In this section, job done in the kitchen were analyzed.

i. Repetitiveness: If cycle time is less than 30 seconds task is defined as high repetitive. In this list, only the reference value is 30 seconds (NIOSH, Elements of Ergonomics Program, 1998).

ii. Forceful movement: When the existence of forceful movement(forcing motion) are investigated, the followings are used as a base;
a. Bending
b. Wrist deviation
c. Twisting
d. Awkward postures.

iii. Static posture: For upright and static postures, availability of a chair etc. for the person to sit and rest from time to time, availability of a pedal to provide motion of feet and legs when the employees are standing and/or availability of a soft platform made of rubber etc. which is higher than the floor will be taken into consideration.

iv. Material handling: At this step availability of a ramp etc. at the entrance of storage to facilitate carrying the materials to the storage, a trolley and lines showing the carrying route in the storage are taken into consideration. In addition, utilization of a cart or trolley for loads heavier than $5 \mathrm{~kg}$ and whether they are carried on a level over the head or not. The optimum carriage level must be at elbow-length and carrying the load over the head would create the greatest risk. In a similar way, the load should be close to the body.

\section{Work station analysis}

In this section, the general situation of the work stations are analyzed.

i. The height of workbench: It is being investigated whether the level of the workbench is at the level of the elbow-length or not.

ii. Design of workbench: The distance between the employee and workbench and tools is taken into consideration. Reference values were taken from IEA Guideline, 2009.

\section{Working environment and layout}

In this section, the general situation of the working environment is examined in terms of temperature, noise, the vibration that the employees are exposed to, the general situation of the aisles and whether they allow the passage of carts or not.

i. Temperature: The ideal level of temperature will be taken as $\left(18-20^{\circ} \mathrm{C}\right)$.

ii. Vibration: It is considered that there is a vibration that the whole body is exposed to.

iii. Noise: It is expected to be below 65 decibels. 
iv. No items in the aisles: It is considered that there should be no unnecessary materials that would prevent moving in the aisle.

v. Enough space for carts/vehicles: According to ILO, the width of the aisles at a hotel should be between $150-200 \mathrm{~cm}$ to allow the passage of two cleaning carts (Ergonomics Checkpoint, ILO, 1996: 4).

\section{Analyzing Jobs, Workstation and Environment}

At this step, the checklist was applied at a hotel and risky jobs and areas were determined. This evaluation is based on the reference values specified in Step 1. Accordingly, the points outside the reference values are determined as critical areas and improvement studies are proposed.

\section{System Improvement}

This step of the study consists system improvement. At this step, the experimental design principles were applied to the areas found ergonomically risky under the light of the data obtained from observations and improvement was made. Using the past sales data, the busiest day and rush hour were determined. Friday was determined as the busiest day and 7:00 PM was determined as the rush hour. Pursuant thereto, it was observed how many minutes it takes for each restaurant personnel to cook identical meals between 7:00 8:00 PM. In every repetition of the experiment a personnel was selected randomly and each time attention was showed for the cooked meal to be the same. In the specified experiment, the response was the meal preparation period and the factors were the height of workbench, underfoot mat and job rotation. Values related to factors and levels are shown in Table 1.

Table 1: Factors and Their Levels

\begin{tabular}{|l|l|l|}
\hline Factors & Levels \\
\hline $\begin{array}{l}\text { Height of the workbench } \\
\text { being at the elbow level }\end{array}$ & 1 & -1 \\
\hline Presence of underfoot mat & 1 & -1 \\
\hline Job rotation & 1 & -1 \\
\hline
\end{tabular}

When Table 1 is examined, it is seen that there are two levels of three factors. In the experiment, the height of the workbench being at the elbow level was symbolized with 1 and it's being under this level was symbolized with -1 . Similarly, the presence of underfoot mat and job rotation are the same. What is meant by job rotation is assigning different jobs to individuals outside of rush hour and enabling them to move to reduce the fatigue ratio. Results of the checklist and experimental design are in the following section.

\section{Result and Discussion}

Three analyses were made in the study. These are job analysis, workstation analysis, work environment and layout analysis. The results of job analysis are summarized in Table 2.

Table 2: Analysing Jobs

\begin{tabular}{|c|c|c|c|c|c|c|}
\hline \multirow{2}{*}{\multicolumn{2}{|c|}{ ERGONOMICS CHECKLIST }} & \multirow{2}{*}{$\begin{array}{l}\text { Housekeeping } \\
\text { Housekeeper }\end{array}$} & \multicolumn{3}{|c|}{ Kitchen } & \multirow{2}{*}{\begin{tabular}{|l|} 
Warehouse \\
Warehouse personnel
\end{tabular}} \\
\hline & & & Baker & Bouchier & Line Cooks & \\
\hline \multirow{4}{*}{ 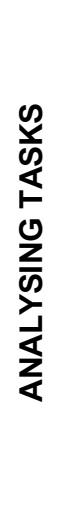 } & $\begin{array}{l}\text { Repetitiveness(Cycle } \\
\text { Time<30 seconds) }\end{array}$ & & $\checkmark$ & $\checkmark$ & $\checkmark$ & \\
\hline & $\begin{array}{l}\text { Forcefull Actions (reach, } \\
\text { ackward posture, backward } \\
\text { posture) }\end{array}$ & $\checkmark$ & & & & \\
\hline & Static Posture & & & $\checkmark$ & $\checkmark$ & \\
\hline & $\begin{array}{l}\text { Material Handling (manual, } \\
\text { overhead,vehicle) }\end{array}$ & & & & & \\
\hline
\end{tabular}


When Table 2 was examined, repetitive movements of baker, butcher and line cook's staff were observed. Since the cycle times of these repetitive movements are less than 30 seconds, they create an ergonomic risk. When cleaning the rooms, housekeepers frequently repeat the motions of bending, reaching out and those that would force their arm and shoulder muscles. Since these motions cause musculoskeletal disorders on the back and waist, ergonomic risks were also found in this kind of works. It is also seen that butchers and chefs who continuously work by standing are at risk.

Another subject examined in the study was the analysis of workbenches or workstations. In this context, housekeeper, baker, butcher, cook and storage personnel are examined once again. The results related to design and height of the workbench for 4 personnel working in this department were summarized in Table 3.

Table 3: Work Station Analysis

\begin{tabular}{|c|c|c|c|c|c|c|}
\hline \multicolumn{2}{|c|}{ ERGONOMICS CHECKLIST } & \multirow{2}{*}{$\begin{array}{l}\text { Housekeeping } \\
\text { Housekeeper }\end{array}$} & \multicolumn{3}{|c|}{ Kitchen } & \multirow{2}{*}{$\begin{array}{l}\text { Warehouse } \\
\text { Warehouse personnel }\end{array}$} \\
\hline & & & Baker & Bouchier & Line Cooks & \\
\hline \multirow{2}{*}{ 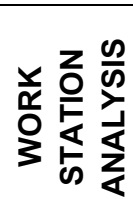 } & Height of Table & & $\checkmark$ & & $\checkmark$ & \\
\hline & Design of Table & & & & $\checkmark$ & \\
\hline
\end{tabular}

When the results of Table 3 are examined, it is seen that the height of table is high for bakers and chefs. Since the height of workbench is not at elbow level, shoulder and neck muscles of the employees work too much and this creates an ergonomic risk.

The final step of the study was to analyze the work environment and layout in terms of ergonomics. The results of the observations made in this context are summarized in Table 4.

Table 4: Workplace Analysis and Layout

\begin{tabular}{|c|c|c|c|c|c|c|}
\hline \multicolumn{2}{|c|}{ ERGONOMICS CHECKLIST } & \multirow{2}{*}{$\begin{array}{l}\text { Housekeeping } \\
\text { Housekeeper }\end{array}$} & \multicolumn{3}{|c|}{ Kitchen } & \multirow{2}{*}{$\begin{array}{l}\text { Warehouse } \\
\text { Warehouse } \\
\text { personnel }\end{array}$} \\
\hline & & & Baker & Bouchier & Line & \\
\hline \multirow{5}{*}{ 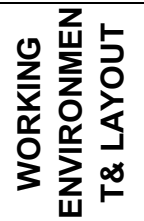 } & Temperature (18-20 C) & & $\checkmark$ & & & \\
\hline & Vibration & & & & & \\
\hline & Noise (Under 65db) & & & & & \\
\hline & No items in the aisles & & & & $\checkmark$ & \\
\hline & Enough space for carts & & & & & \\
\hline
\end{tabular}

When Table 4 is examined, it is seen that the working environment of the bakery personnel is above the ideal temperature due to the nature of the work and the objects preventing the traffic of cooks and materials in the kitchen are located in the aisle. When the overall evaluation is made, the riskiest personnel in terms of ergonomics are the chefs. For this reason, it was decided to make an improvement for restaurant personnel. In this context, one $2^{3}$ and one four-repetitive full factorial experimental design were created. Results of the Design of Experiment (DOE) are summarized below. 
Table 5: ANOVA Results

\begin{tabular}{|llllll|}
\hline Analysis of Variance & & & & & \\
\hline & DF & Adj SS & Adj MS & F-Value $P$-Value \\
\hline Source & 7 & 15.6447 & 2.23496 & 7.17 & 0.000 \\
\hline Model & 3 & 14.5384 & 4.84615 & 15.55 & 0.000 \\
\hline Linear & 1 & 4.1328 & 4.13281 & 13.26 & 0.001 \\
\hline Factor 1 & 1 & 7.7028 & 7.70281 & 24.72 & 0.000 \\
\hline Factor 2 & 1 & 2.7028 & 2.70281 & 8.68 & 0.007 \\
\hline Factor 3 & 3 & 0.5284 & 0.17615 & 0.57 & 0.643 \\
\hline 2-Way Interactions & 1 & 0.4753 & 0.47531 & 1.53 & 0.229 \\
\hline Factor 1*Factor 2 & 1 & 0.0003 & 0.00031 & 0.00 & 0.975 \\
\hline Factor 1*Factor 3 & 1 & 0.0528 & 0.05281 & 0.17 & 0.684 \\
\hline Factor 2*Factor 3 & 1 & 0.5778 & 0.57781 & 1.85 & 0.186 \\
\hline 3-Way Interactions & 1 & 0.5778 & 0.57781 & 1.85 & 0.186 \\
\hline Factor 1*Factor 2*Factor 3 & 24 & 7.4775 & 0.31156 & & \\
\hline Error & 31 & 23.1222 & & & \\
\hline Total & & & & & \\
\hline
\end{tabular}

summarizes ANOVA results. According to ANOVA results, it is seen that all factors affect the outcome. It was seen that $p$ values were significant at the $\alpha=0.05$ level for each factor. In this case, it is also seen from $p$ values that all arrangements directly affect the preparation period of the plate. In addition to these, it is necessary to consider the direction and intensity of the factors. The results in Table 6 summarizes this situation.

Table 6: Effect Levels of Factors

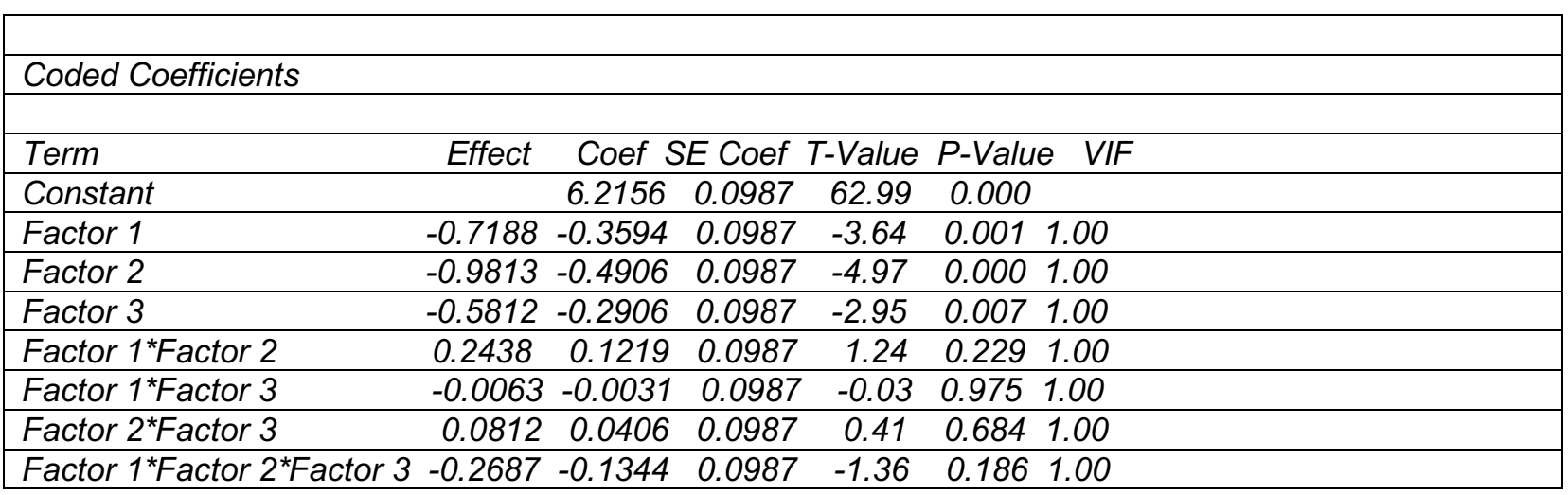

When the results presented in Table 6 are examined, the intensity and direction of each factor's effect are seen in the "effect" column. The effect values for factors 1, 2 and 3 in this column are negative. It gives the direction of the relationship between the factors and response values. In other words, the increase in the factor causes a decrease in response value. This means that the existence of the factor shortens the preparation period of the plate. When the intensity of factors are examined in the same column when the absolute values are examined independently of negative values it can be said that Factor 2 has the greatest effect and respectively Factors 1 and 3 also affect the results. The results, by which the relationship between the factors is investigated, are shown in Figure 1. 


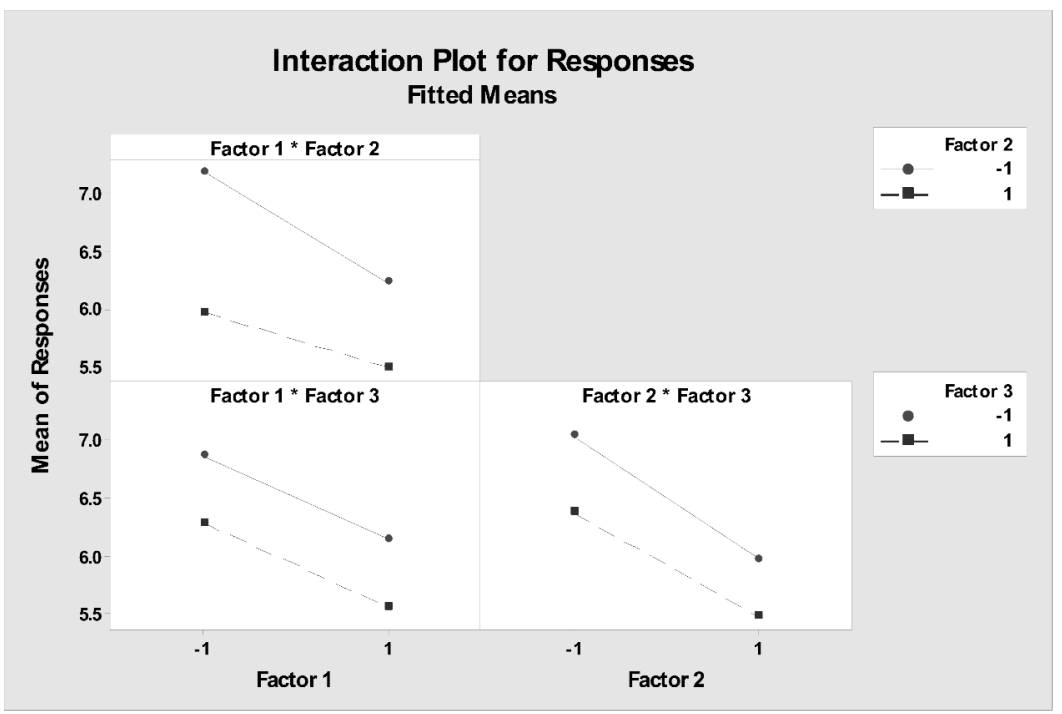

Figure 1: Interaction effect of factors

When Diagram 1 is examined, it is seen that there is no interaction between the factors. In the upper lefthand corner of the diagram, the relationship between factors 1 and 2, right under it, the relationship between factors 1 and 3 and in the bottom right-hand corner, the relationship between factors 3 and 3 are seen. As the lines run parallel to each other in all images, it can be said that there is no relationship between the factors.

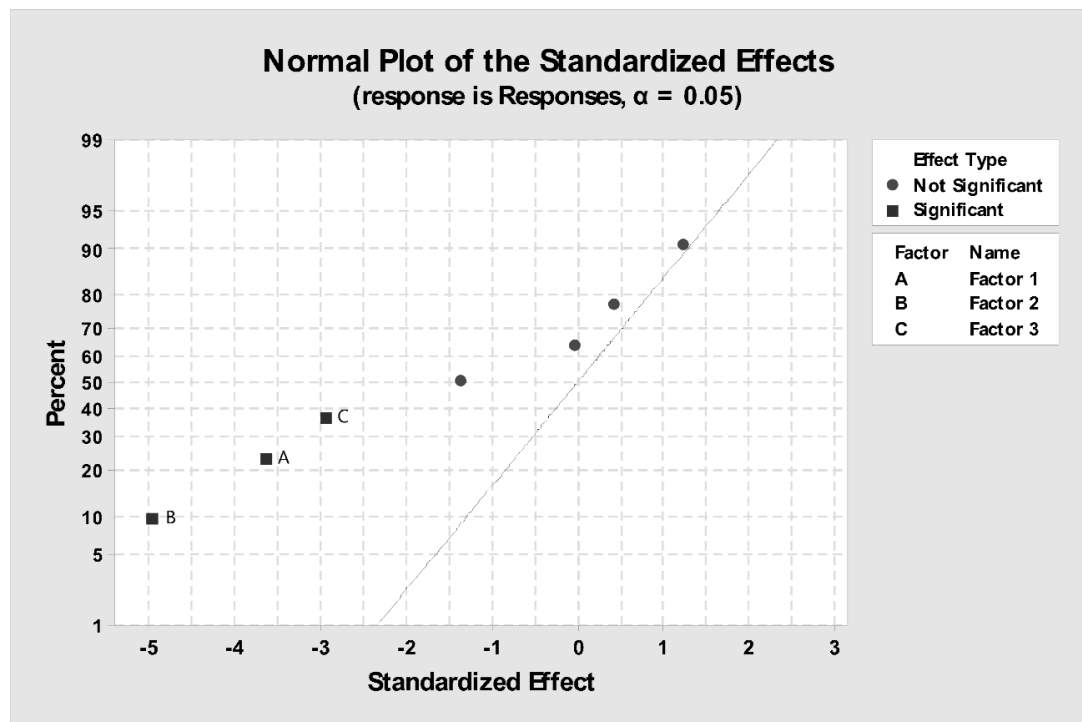

Figure 2: Standardized effects for residuals

When Figure 2 is examined, it observed seen that residuals are in accord with the normal distribution. In this case, there is no need for any correction in data. Upon completion of all analyses, it is seen that three factors used in the experiment have negative effects on plate preparation periods of the chefs and in terms of impact, the greatest effect is caused by Factor 2 (presence of underfoot mat) comes first, Factor 1 (height of the workbench is at elbow level) comes second and Factor 3 (job rotation) comes third. 


\section{Discussion}

Analysis and improvement of the job in terms of ergonomics are important with regard to personal health and productivity. A deficiency or nonconformity in these areas will decrease the productivity of employees and consequently cause loss of time and cost increase for the establishment. It was observed during the research that hands and wrists are intensely on the move in the fields of repetitive jobs. And this will cause physical problems in time and also the loss of work.

Another inconvenience of repetitive motions is that they cause monotony and attention deficiency in time. Particularly when it is considered that the kitchen personnel working in the processes of baking, butchering, and meal preparation work with cutlery and are exposed to high temperatures, monotony, and loss of work would also cause work accidents. For this reason, it is suggested job rotation and work diversification in these sections during the shifts.

In particular, it was frequently observed that housekeepers often bend, reach out, bend their waists and knees for a long time move their wrists in big angles and their arms exert excessive pressure on the surface while they work. In order to remove these ergonomic risks particularly when cleaning baths and outdoor areas it is recommended to use apparatus with long handles as this will stretch out the effort arm and decrease the applied force.

Another investigation was examining the workbenches and/or work tables in terms of ergonomics. In this context, it was observed that workbenches of bakers and chefs are high. The optimum solution is designing these workbenches and tables by considering the anthropometric measurements of people. It is advised to the establishments that consider this would be costly, to uplift them with a pallet supported from below or a thick mat up to the elbow level. Otherwise, fatigue ratio will increase and productivity will decrease.

When the design of workbenches is examined, it was seen that the workbenches of the chefs are not designed in such a manner that would facilitate accessing the materials and tools. It was observed that frequently used tools are out of reach and employees are forced to reach out on the workbench for continuous works. It is proposed to re-design the workbenches to shorten the distances between the person and work especially for repetitive works.

When the analyses of work environment and layout are examined, it is seen that bakery personnel are exposed to high temperature and smoke. Therefore, it is recommended job rotation, better ventilation and protective clothing in this department. Another issue that affects the speed of work and productivity is leaving the aisles to allow passage of materials and people. It is recommended to remove the materials and manual handling tools from the aisles in the section where the chefs work. Placing the materials on shelves designed on the workbenches is recommended as a solution.

\section{Conclusions}

The new check list for hotel kitchens were established in this study. Factorial design results showed that all factors shortens the preparation period of the plate respectively. But results also showed that the greatest effect is caused by Factor 2 (presence of underfoot mat) comes first, Factor 1 (height of the workbench is at elbow level) comes second and Factor 3 (job rotation) comes third.

This study was conducted in the labor-intensive sections of every hotel, such as housekeeping and kitchen. As the considerable part of the operations in these departments are manual, it is important to accord the work, workbenches, and environment with human beings in terms of decreasing the ergonomic risks. As the types of hotels change, their functional units also change. For example, units like swimming pools, beaches, beach bars, beach restaurants are included at resort hotels. Therefore, it is recommended to review this study by also considering those units.

Since ergonomic researches generally begin and develop with manufacturing, there are not many implementations in the service industry. Whereas it is necessary to investigate the ergonomic risks in laborintensive and work pace-intensive places such as hospitals, catering companies, accommodation businesses, vehicle repair shops etc. 


\section{Mogol Sever / International Journal of Research in Business and Social Science,}

Vol 8 No 2, 2019 ISSN: 2147-4486

There are numerous international organizations dealing with ergonomic studies. As a continuation of this study, a specific line of work should be chosen, ergonomic risks should be determined and a training program should be developed. Anthropometric measurements of each country differ. These measurements should be taken into consideration when designing work clothing, workbenches, tools-equipment etc. It is necessary to work with a big sample suitable for normal distribution to take these measurements. Even though it is a bit time consuming, it is a solution to eliminate the ergonomic risks. Therefore, researchers are advised to conduct studies regarding anthropometric measurements in various lines of work by considering gender differences.

Finally, Factor 3 was addressed in the experiment. This experiment can be repeated in terms of the equipment used etc.

\section{References}

Chyuan, J. A., C. Du, Yeh, W., Li.,C. (2004). Musculoskeletal disorders in hotel restaurant workers. Occupational Medicine. 54: 55-57 https://doi.org/10.1093/occmed/kqg108

Demsey, P.G.,Filiaggi,A.J. (2006). Cross-sectional investigation of task demands and musculoskeletal discomfort among restaurant wait staff. Ergonomics. 49 (1):93-106. https://doi.org/10.1080/00140130500415225.

Gentzler, M.D., Smither, J.A. (2012). Using practical ergonomic evaluations in the restaurant industry to enhance safety a comfort: a case study. Work 41:5529-5531. . https://doi.org/10.3233/WOR-20120872-5529.

Gogri, P., Josh, V.A., Dabadgha, R., Rairikar, S., A. Shyam, A., Sancheti, P. (2007). Prevalence of musculoskeletal disorders in restaurant workers. Indian Journal of Physical Therapy. 5 (1): 6-19.

Haukka, E., Leino-Arjas, P., Solovieva, S., Ranta, R., Viikari- Juntura. E., Riihimäki, H. (2006). Co-occurrence of musculoskeletal pain among female kitchen workers. International archives of Occupational and Environmental Health. 80(2): 141-148. . https://doi.org/10.1007/s00420-006-0113-8

Kalkis, H., Roja, Z., Kalkis, V. (2014). Physical load analysis in hotel cleaning work. Agronomy Research. 12 (3): 843-850.

Kapulainen, $\mathrm{H}$. Ergonomics in a restaurants case study a how is the ergonomics situation in Amarillo, Jyvaskyla seen by it is employees. Degree programme in facility management. Jamk University of applied sciences. 2010. Keyserling, W.M., Brouwer, M., Silverstein, B.A. (1992). A checklist for evaluating ergonomic risk factors resulting from awkward postures of the legs, trunk and neck. International Journal of Industrial Ergonomics.9: 283-304. http://dx.doi.org/10.1016/01698141(92)90062-5.

Liu, L.W., Wang, A.H., Hwan, S., Lee, Y., Chen, C. (2011). Prevalence and risk factors of subjective musculoskeletal symptoms among cooks in Taiwan. Journal of the Chinese Institute of Industrial Engineers. 28 (5): 327-335. https://doi.org/10.1080/10170669.2011.573005

Mehlum, I.S., Kristensen, P., Kjuus, H., Wergeland, E. (2008). Are occupational factors important determinants of socioeconomic inequalities in musculoskeletal pain. Scand J Work Environ Health. 34(4): 250-259. https://doi.org/10.5271/sjweh.1269

Parmar, S., Dalal, P. (2017). A Study of musculosketal disorder among housekeeping staff in hotel industry. International Journal of Home Science. 23(3):83-85. http://www.homesciencejournal.com/archives/2017/vol3issue3/PartB/3-3-32-522.pdf

Rahman, M.N.A., Jaffar, M.S., Hassan, M.F., Ngali, M.Z., Pauline, O. (2017). Exposure level of ergonomic risk factors in hotel industries. International Research and Innovation Summit. IOP Conference

Series: Materials Science and Engineering, May, Malaysia. 226:1-10. https://doi.org/10.1088/1757-899X/226/1/012018 
Syed-Ali, S.A., Kamat, S.R., Mohamed, S.B. (2018). Analysis awkward posture at food production activity using rula assessment. Journal of Fundamental and Applied Sciences. 10(15): 619-632. http://dx.doi.org/10.4314/jfas.v10i1s.44

Wills, A.C., Davis, K.G, Kotowski, S. E.(2016). Quantification of ergonomics exposures for restaurant servers. Journal of Ergonomics. 3: 1-11.

Elements of Ergonomic Programmes 1998. Tray 5-A. "General Ergonomics Risk Analysis Checklist NIOSH". https://www.cdc.gov/niosh/docs/97-117/pdfs/97-117.pdf. Accessed 21.01.2018.

Ergonomics Guideline in 2010 IEA.

http://www.icohweb.org/site/multimedia/pubblicazioni/ICOH\%20and\%20IEA\%20Ergonomics\%20 Guidelines\%20April\%202010.pdf. Accessed 23.02.2018.

Ergonomics and Trauma Injuries: basics for housekeeper manager document of disorder OSHA. https://ergonomics.osu.edu/sites/ergonomics.osu.edu/files/uploads/Housekeeper\%20Manageme nt\%20Ergonomics\%20Training\%20Handout.pdf. Accessed 02.01.2018.

Work Improvement for Small Enterprises Programme (2018). http://www.ilo.org/wcmsp5/groups/public/--ed_protect/---protrav/travail/documents/instructionalmaterial/wcms_152474.pdf._Accessed 04.02.2018. 